\title{
A COMPARATIVE STUDY OF CARDIOVASCULAR STABILITY IN UNILATERAL AND BILATERAL SPINAL BLOCK IN LOWER LIMB SURGERY (FRACTURE TIBIA)
}

\author{
Parmod Kumar1, Tejinderpal Kaur Grewal², Gurpreet Kaur Atwal'3 , Devinder Goyal ${ }^{4}$, Charu Sharma 5
}

1 Professor and HOD, Department of Anaesthesia, GMC, Patiala, Punjab, India.

2 Professor, Department of Anaesthesia, GMC, Patiala, Punjab, India.

${ }_{3}^{3}$ Senior Resident, Department of Anaesthesia, SGRD, Amritsar, Punjab, India.

4Junior Resident, Department of Anaesthesia, GMC, Patiala, Punjab, India.

5Junior Resident, Department of Anaesthesia, GMC, Patiala, Punjab, India.

\section{BACKGROUND}

ABSTRACT

Spinal anaesthesia is an effective alternative to general anaesthesia when the surgical site is located on the lower extremities, perineum or lower body wall. It is easy to perform and results in sympathetic block, sensory analgesia and motor block. There are several disadvantages of spinal anaesthesia, among which are bradycardia and hypotension. Unilateral spinal anaesthesia limits the motor, sensory and sympathetic block to one side and thus have fewer haemodynamic complications.

The aim of our study was to compare cardiovascular stability in unilateral versus bilateral spinal block in lower limb surgery (Fracture Tibia) using $3 \mathrm{~mL}$ of $0.5 \%$ heavy bupivacaine.

\section{MATERIALS AND METHODS}

This non-randomised controlled trial was performed in 100 patients who were assigned to two groups. Both groups received $3 \mathrm{~mL}$ (15 mg) of $0.5 \%$ hyperbaric bupivacaine intrathecally in lateral decubitus position at L4-L5 lumbar interspace with operating limb down. In Group I (Bilateral group), patients were immediately turned supine. In Group II (Unilateral group) patients were kept in lateral position for 10 minutes. Onset of sensory and motor block, haemodynamic changes, regression of motor block and incidence of complications were recorded. The sample size estimation was also done at conveniences.

\section{RESULTS}

By giving $3 \mathrm{~mL}$ of $0.5 \%$ hyperbaric bupivacaine, haemodynamic parameters (Heart rate, blood pressure, peripheral saturation of oxygen, respiratory rate) were statistically comparable in both groups. The mean onset of sensory blockade was faster in Group II (Unilateral Group) as compared to Group I (Bilateral Group). The results showed statistically significant increase in the duration of postoperative analgesia and requirement of postoperative analgesics was significantly less in Group II (Unilateral Group) as compared to Group I (Bilateral Group). So, the effect is more profound and longer lasting in the unilateral group.

\section{CONCLUSION}

Using $3 \mathrm{~mL}$ of $0.5 \%$ hyperbaric bupivacaine, unilateral spinal block when compared with bilateral spinal block, the haemodynamic changes were found to be statistically insignificant. Unilateral spinal block provides early onset of sensory and motor block, dense motor block with increase in duration of postoperative analgesia.

\section{KEY WORDS}

Unilateral Spinal Block, Bilateral Spinal Block, Bupivacaine, Fracture Tibia.

HOW TO CITE THIS ARTICLE: Kumar P, Grewal TK, Atwal GK, et al. A comparative study of cardiovascular stability in unilateral and bilateral spinal block in lower limb surgery (fracture tibia). J. Evolution Med. Dent. Sci. 2018;7(40):4347-4351, DOI: $10.14260 /$ jemds/2018/970

\section{BACKGROUND}

Subarachnoid (Spinal) block is a safe and effective alternative to general anaesthesia when the surgical site is located on the lower extremities, perineum (eg, surgery on the genitalia or anus) or lower body wall (eg, inguinal herniorrhaphy). It is easy to perform and results in sympathetic block, sensory analgesia and motor block.[1]

'Financial or Other Competing Interest': None.

Submission 29-03-2018, Peer Review 14-09-2018,

Acceptance 21-09-2018, Published 01-10-2018.

Corresponding Author:

Dr. Gurpreet Kaur Atwal,

Senior Resident,

SGRD, Amritsar, 44-B, New Kangra Colony,

Near Partap School, Amritsar, Punjab, India.

E-mail: preetatwal14@gmail.com

DOI: $10.14260 /$ jemds $/ 2018 / 970$

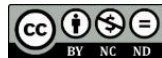

Spinal anaesthesia is superior to general anaesthesia in providing postoperative analgesia and maintained better perioperative haemodynamic stability without increasing adverse side effects. Several local anaesthetics (Procaine, tetracaine, lignocaine, bupivacaine and levobupivacaine) are used for spinal anaesthesia. Bupivacaine is three to four times more potent and has longer duration of action than lignocaine.[2] There are several disadvantages of spinal anaesthesia, among which are bradycardia and hypotension. Hypotension is the most frequent side effect occurring in more than $30 \%$ of patients.[3]

Unilateral spinal anaesthesia limit the motor, sensory and sympathetic block to one side, thus having several advantages including fewer haemodynamic complications, selective block on the operated side, better mobilisation during the recovery period, lower incidence of postoperative urine retention as well as good patient satisfaction. ${ }^{[4,5,6]}$ Also, there is reflex vasoconstriction in the non-blocked side as a compensation for the sympathectomised side.[5] 
The present study was conducted to compare cardiovascular stability in unilateral versus bilateral spinal block in lower limb surgery (Fracture Tibia) using $3 \mathrm{~mL}$ of $0.5 \%$ heavy bupivacaine.

\section{MATERIALS AND METHODS}

The non-randomised controlled trial was conducted in 100 patients undergoing lower limb surgery (Fracture tibia) under spinal anaesthesia in Government Medical College and Rajindra Hospital, Patiala. After taking a written informed consent, these patients were randomly divided into two groups with 50 patients in each group. Study by convenient allocation technique. Since the duration of the study was few months. The patients were selected by convenience allocation technique. The sample size estimation was also done at conveniences. Both groups received $3 \mathrm{~mL}(15 \mathrm{mg})$ of $0.5 \%$ hyperbaric bupivacaine intrathecally in lateral decubitus position at L4-L5 lumbar interspace with operating limb down. In Group I (Bilateral group), patients were immediately turned supine. In Group II (Unilateral group), patients were kept in lateral position for 10 minutes. Inclusion criteria were ASA grade I and II, age between 20 and 60 years of age. Body mass index < 30. Normal coagulation profile Exclusion criteria were patient's refusal. Any spine abnormality altered coagulation profile, allergy to local anaesthetic, recent myocardial infarction, significant aortic stenosis, patients with neurological disorders, cardiac or respiratory system failure, any major hepatic or renal problem. Pre-anaesthetic check-up was done one day before surgery in every patient.

Basic lab investigations (Haemoglobin, bleeding time, clotting time, fasting blood sugar, blood urea, serum creatinine, serum electrolytes, ECG, complete urine examination and other relevant investigations if any were done in all the patients and were explained in detail about the procedure of the spinal anaesthesia during the preanaesthetic visit. Patients were familiarised with the Visual Analogue Scale (VAS) (0- No pain, 10- Worst pain) a day before surgery.

Patients were advised 8 hours of fasting and premedicated with Tab. Ranitidine $150 \mathrm{mg}$, given previous night orally. Tab. Ranitidine $150 \mathrm{mg}$ and Tab. Lorazepam $1 \mathrm{mg}$ were given orally at 6 am on the day of surgery. Intravenous access was secured with $18 \mathrm{G}$ cannula. All patients were preloaded with $15 \mathrm{~mL} / \mathrm{kg}$ of Ringer's lactate solution.

In the operating room, after attaching routine monitors (Electrocardiograph, non-invasive blood pressure, pulse oximeter), baseline BP (Systolic, diastolic and mean), heart rate, respiratory rate and peripheral oxygen saturation (Sp02) were recorded before intrathecal injection. Patients were positioned in lateral decubitus position. Under all aseptic precautions parts were cleaned and draped and L4-L5 space was identified and $2 \mathrm{~mL}$ of $2 \%$ lignocaine was infiltrated locally. Subarachnoid block was given at the L4-L5 interspace with a 23G Quincke's spinal needle and $3 \mathrm{~mL}$ of $0.5 \%$ hyperbaric bupivacaine was injected intrathecally at the rate of $0.2 \mathrm{~mL} / \mathrm{sec}$. The patients were immediately turned supine in bilateral group and kept in lateral position with operating limb down for 10 minutes in unilateral group. Oxygen was provided via Venturi mask at the rate of $4 \mathrm{~L} / \mathrm{min}$.

Sensory block was assessed by pinprick method and motor blockade by using Modified Bromage Scale checked every 2 minutes after injecting the drug intrathecally till
Visual Analogue Scale score of 1 or less was obtained at T10 level and a Modified Bromage Score of 3 was obtained. The surgical procedure was started after obtaining the sensory block at T10 level.

Heart rate and rhythm, arterial blood pressure, respiratory rate, $\mathrm{SpO} 2$ was recorded after every 5 minutes for 30 minutes after intrathecal injection and thereafter every 15 minutes till end of surgery. Heart rate less than 60 per minute was taken as bradycardia and was treated with intravenous injection atropine $0.3 \mathrm{mg}$. Fall in systolic blood pressure less than $90 \mathrm{mmHg}$ or more than 20 percent of fall from baseline value was taken as hypotension. It was treated with intravenous bolus dose of mephentermine $5 \mathrm{mg}$.

Postoperatively, in patients with a VAS score of $>4$, intramuscular diclofenac $(75 \mathrm{mg}$ ) was administered as rescue analgesic and the duration of analgesia (time from the administration of intrathecal drugs and administration of first rescue analgesic) was noted. Patients were also assessed for side-effects like nausea, vomiting, hypotension, pruritis, shivering, urinary retention and bradycardia. All the data was analysed statistically and accordingly compared between the two groups.

Descriptive statistics was done for all data and were reported in terms of mean and variance. Suitable statistic tests of comparison were applied. All the variables were analysed with unpaired t-test. Statistical significance was taken as $p$-value $<0.05$. The data was analysed using SPSS version 22 .

\section{RESULTS}

Both the groups were comparable with respect to age, gender and weight distribution. The mean heart rate of all patients was comparable in both the groups at all times. The difference in the mean heart rate between the two groups was statistically insignificant ( $p$ value $>0.05$ ).

The mean systolic blood pressure, mean diastolic blood pressure and mean arterial blood pressure of both the groups was comparable at all the times. Starting from the fifth minute after injection, the values were statistically lower in both the groups. But the difference in the mean systolic blood pressure, mean diastolic blood pressure and mean arterial pressure between the two groups was statistically insignificant ( $p$ value $>0.05$ ).

At all times, the mean SpO2 levels remained fairly constant above $95 \%$ in all patients in both the groups. The difference in SpO2 was statistically insignificant ( $p$ value $>0.05$ ).

The difference in the mean respiratory rate of patients in the two groups was statistically insignificant ( $p$ value $>0.05$ ). There were no statistical differences between the groups in the surgical time.

There is no difference in the mean Modified Ramsay Sedation Score (MRSS) of patients in the two groups. It means that both the groups were statistically insignificant.

The mean Visual Analog Score (VAS) from 5 minutes till 120 minutes were comparable in both the groups. The difference is statistically insignificant ( $p$ value $>0.05$ ). At 135 minutes, the mean VAS score in Group I is higher than the score in Group II. The difference is statistically significant ( $p$ value $<0.05$ ). The mean VAS scores after 135 minutes till 180 minutes in Group I is higher than the score in Group II. The difference is statistically highly significant ( $p$ value $<0.05$ ). 
As shown in table, the mean Modified Bromage Score (MBS) at 5 mins was comparable in both the groups. The difference was statistically insignificant ( $p$ value $>0.05$ ). At 10 minutes, the difference was statistically highly significant ( $\mathrm{p}$ value < 0.05). At 15 minutes, the difference was statistically insignificant ( $p$ value $>0.05$ ). Thus, indicates early onset of motor block in Group II as compared to Group I.

Mean time of onset of sensory block was 7.78 mins +/0.790 min in Group I and 6.86 mins +/- 0.969 mins in Group II. The difference was statistically highly significant ( $\mathrm{p}$ value $<0.05$ ). Thus, indicates early onset of sensory block in Group II as compared to Group I.

The postoperative Visual Analog Score ( VAS ) after 30 minutes till 120 minutes post-operatively were lower in Group II as compared to Group I, the difference being statistically non-significant upto $30 \mathrm{mins}$ interval and highly significant ( $p$ value $<0.05$ ) at and after 45 mins interval.
This indicates prolonged duration of postoperative analgesia in Group II as compared to Group I.

The mean duration of spinal anaesthesia was 222.54 mins +/- 8.455 mins in Group I and 244.34 mins +/- 7.104 mins in Group II. The difference was statistically highly significant ( $p$ value < 0.05). The mean postoperative analgesia was prolonged in Group II as compared to Group I. The difference being statistically highly significant ( $p$ value $<0.05$ ). The mean recovery of motor blockade was prolonged in Group II as compared to Group I. The difference being statistically highly significant ( $\mathrm{p}$ value $<0.05$ )

The difference in the mean postoperative rescue analgesic requirement was statistically highly significant in both the groups ( $\mathrm{p}$ value $<0.05$ ) indicating no requirement of rescue analgesics in the postoperative period in Group II as compared to Group I.

The percentage of patients experiencing various side effects were similar in both the groups. The difference was statistically non-significant ( $p$ value $<0.05$ ).

\begin{tabular}{|c|c|c|c|c|c|c|}
\hline \multirow{2}{*}{ Variable } & \multicolumn{2}{|c|}{ Group I } & \multicolumn{2}{c|}{ Group II } & \multirow{2}{*}{ P value } & \multirow{2}{*}{ Significance } \\
\cline { 2 - 6 } & Mean & S.D. +/- & Mean & S.D. +/- & & NS \\
\hline Age & 37.06 & 12.02 & 40.60 & 12.33 & 0.149 & NS \\
\hline Body weight & 67.00 & 4.64 & 66.28 & 7.86 & 0.579 & NS \\
\hline Surgical time & 88.00 & 13.05 & 84.80 & 12.53 & 0.166 & \\
\hline \multicolumn{7}{|c|}{ Table 1. Demographic and Operative Data } \\
\hline
\end{tabular}

\section{Haemodynamic Variables}
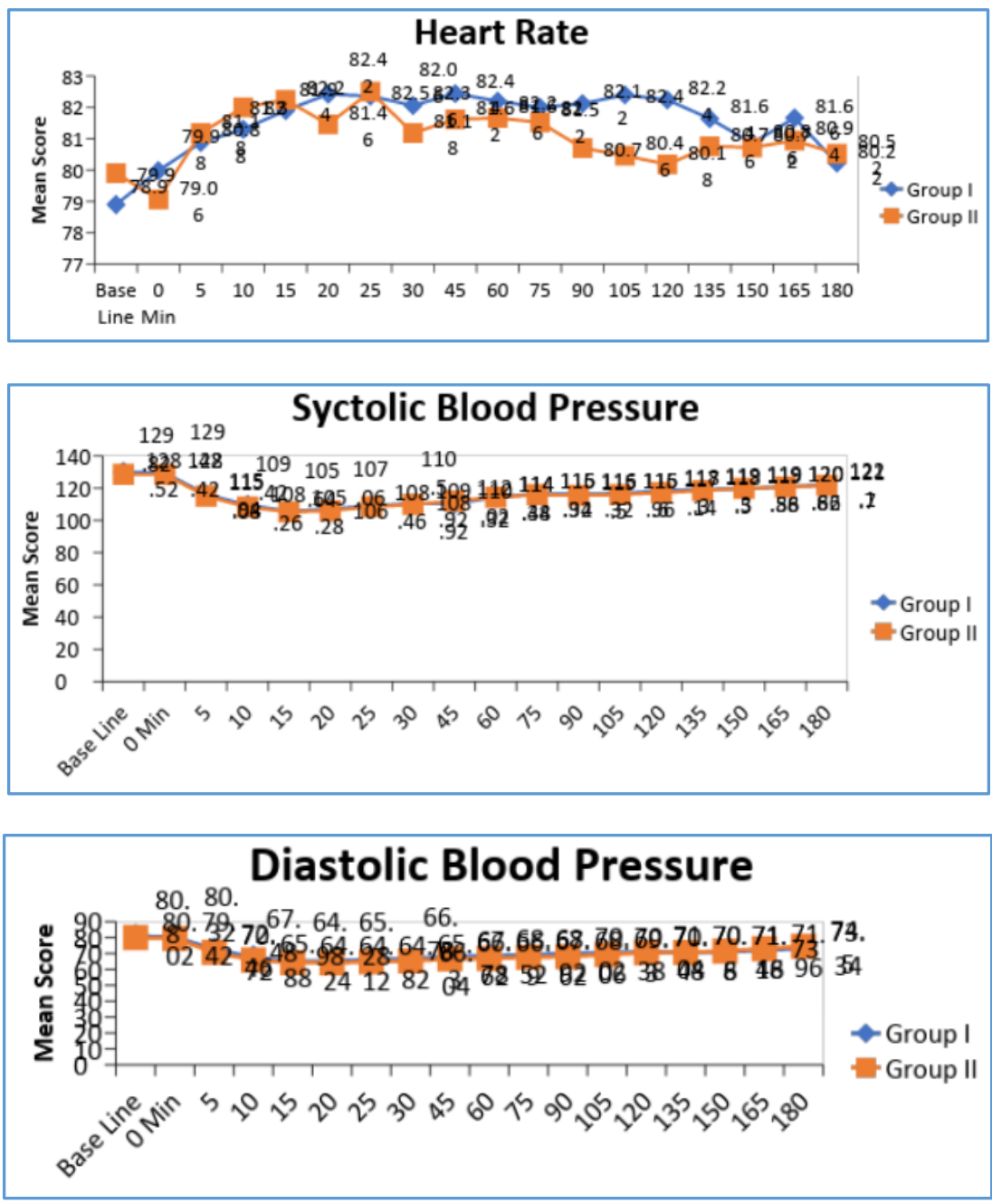


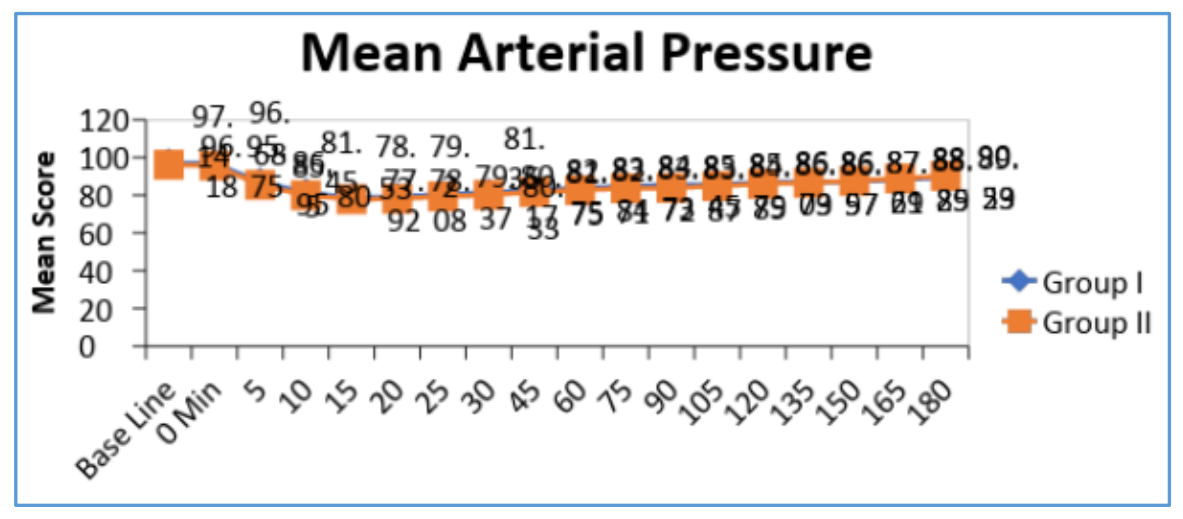

\begin{tabular}{|c|c|c|c|c|}
\hline Groups & Mean & S.D +/- & P value & \multirow{2}{*}{ Significance } \\
\hline Group I & 7.78 & 0.790 & \multirow{2}{*}{ HS } \\
\hline Group II & 6.86 & 0.969 & \\
\hline \multicolumn{2}{|c|}{ Table 2. Time of Onset of Sensory Block (Mins) } \\
\hline
\end{tabular}

\begin{tabular}{|c|c|c|c|c|c|c|}
\hline \multirow{2}{*}{ MBS } & \multicolumn{2}{|c|}{ Group I } & \multicolumn{2}{c|}{ Group II } & \multirow{2}{*}{ P value } & \multirow{2}{*}{ Significance } \\
\cline { 2 - 6 } & Mean & S.D +/- & Mean & S.D +/- & 0.388 & NS \\
\hline 5 mins & 2.22 & 0.465 & 2.18 & 0.495 & 0.001 & HS \\
\hline 10 & 1.74 & 0.443 & 1.40 & 0.00 & 1.000 & NS \\
\hline 15 & 1.00 & 0.00 & 1.00 & \multicolumn{2}{c}{ Table 3. Modified Bromage Scale } \\
\hline
\end{tabular}

\begin{tabular}{|c|c|c|c|c|c|c|}
\hline \multirow{2}{*}{ Variable } & \multicolumn{2}{|c|}{ Group I } & \multicolumn{2}{c|}{ Group II } & \multirow{2}{*}{ P value } & \multirow{2}{*}{ Significance } \\
\cline { 2 - 7 } & Mean & S.D +/- & Mean & S.D +/- & & HS \\
\hline Duration of spinal anaesthesia (mins) & 222.54 & 8.455 & 244.34 & 7.104 & $<0.001$ & HS \\
\hline Post-op analgesia (mins) & 134.82 & 15.107 & 159.34 & 14.007 & $<0.001$ & HS \\
\hline Recovery of Motor Blockade (mins) & 168.54 & 7.481 & 182.56 & 7.608 & $<0.001$ & \\
\hline \multicolumn{3}{|c|}{ Table 4 } \\
\hline
\end{tabular}

\section{DISCUSSION}

Spinal anaesthesia is widely used in clinical practice, but it has the risk of potential complications. The most common drawback is post-spinal block hypotension, which was found to be related to the degree of sympathetic block.[4,7] Hypotension occurs in more than $30 \%$ of patients. ${ }^{[3]}$ The present study was a non-randomised controlled trial conducted on 100 patients of ASA Grade I and II of age group 20 - 60 years undergoing lower limb surgery (Fracture tibia) under spinal anaesthesia in Government Medical College and Rajindra Hospital, Patiala. After taking a written informed consent, these patients were randomly divided into two groups with 50 patients in each group. We evaluated the comparison of cardiovascular stability in unilateral versus bilateral spinal block in lower limb surgery (fracture tibia).

In Group I (Bilateral Group), patients received $3 \mathrm{~mL}(15$ $\mathrm{mg}$ ) of $0.5 \%$ hyperbaric bupivacaine intrathecally in lateral decubitus position at L4-L5 lumbar interspace and were immediately turned supine. In Group II (Unilateral Group), patients received $3 \mathrm{~mL}$ ( $15 \mathrm{mg}$ ) $0.5 \%$ hyperbaric bupivacaine intrathecally in lateral decubitus position at L4-L5 lumbar interspace with operating limb down and were kept in lateral position for 10 minutes.

In our study, both the groups were comparable in their anthropometric data and duration of surgery.

In terms of haemodynamic parameters, the mean heart rate, mean systolic blood pressure, mean diastolic blood pressure, mean arterial blood pressure of both the groups were comparable at all the times. Starting from the fifth minute after injection the values of SBP, DBP and MAP were significantly lower to baseline in both the groups. But there was no significant difference in the mean systolic blood pressure, mean diastolic blood pressure and mean arterial pressure between the two groups. This result is in concordance with the study conducted by Bridenbaugh $\mathrm{P}$ and Greene $\mathrm{N}$ et al[8] (2009) who found that there was no significant difference between the groups in terms of haemodynamics when higher doses of bupivacaine were used. Waleed A. Almarakbi and Hazem M. Fawzi[9] (2012) conducted a study and found that there was no significant difference between the groups in terms of haemodynamics with higher doses of bupivacaine.

For sensory level, early onset of sensory block was found in Group II as compared to Group I. The mean time of onset of sensory block was $7.78 \mathrm{mins}+/-0.790 \mathrm{~min}$ in Group I and 6.86 mins +/- $0.969 \mathrm{~min}$ in Group II. The difference was statistically highly significant ( $p$ value $<0.05)$. The postoperative VAS scores after 30 minutes till 120 minutes postoperatively were lower in Group II as compared to Group I. The difference being statistically highly significant ( $\mathrm{p}$ value $<0.05$ ). Prolonged duration of postoperative analgesia in Group II as compared to Group I.

For assessment of motor power using modified Bromage scale, early onset of motor block was seen in Group II as compared to Group I. At 10 minutes, the difference in mean 
modified Bromage score was statistically highly significant ( $\mathrm{p}$ value $<0.05$ ). At 15 minutes, the difference was statistically insignificant ( $\mathrm{p}$ value $>0.05$ ). The mean recovery of motor blockade was prolonged in Group II as compared to Group I, the difference being statistically highly significant ( $p$ value $<0.05)$.

These findings are similar study conducted by Atef $\mathrm{H}$ and El-Kasaby A et al[10] (2010), who found that unilateral spinal anaesthesia provides faster onset of sensory and motor block. Faruk C et al[11] (2014) conducted a study and found that unilateral spinal anaesthesia provides faster onset of sensory and motor block.

The mean duration of spinal anaesthesia was $222.54 \mathrm{mins}$ +/- 8.455 mins in Group I and 244.34 mins +/- 7.104 mins in Group II. The difference was statistically highly significant ( $p$ value $<0.05$ ).

More dense spinal anaesthesia was seen in Group II as compared to Group I, as the mean duration of spinal anaesthesia, post-operative analgesia and mean recovery was prolonged in Group II as compared to Group I. The difference being statistically highly significant ( $\mathrm{p}$ value $<0.05$ ).

These findings are consistent with the study conducted by Esmaoğlu et al[12] (1998) who found that unilateral spinal block provides longer duration of spinal analgesia and provides longer duration of block. A study conducted by Fanelli G et al (2000) found that unilateral spinal anaesthesia provides longer duration of motor block with higher doses of bupivacaine. Pakize K and Anil M et al[13] (2006) conducted a study and found that unilateral spinal anaesthesia provides longer duration of motor block.

The percentage of patients experiencing various side effects were similar in both the groups. The difference was statistically non-significant ( $p$ value $<0.05$ ).

\section{CONCLUSION}

1. We observed that the groups were comparable with respect to the demographic data (age, weight), diagnosis and duration of surgery.

2. By giving $3 \mathrm{~mL}$ of $0.5 \%$ hyperbaric bupivacaine, haemodynamic parameters (heart rate, blood pressure, peripheral saturation of oxygen, respiratory rate) were statistically comparable in both the groups.

3. The mean onset of sensory blockade was faster in Group II (Unilateral Group) as compared to Group I (Bilateral group).

4. The results showed statistically significant increase in the duration of postoperative analgesia and requirement of postoperative analgesics was significantly less in Group II (Unilateral Group) as compared to Group I (Bilateral Group). So, the effect is more profound and longer lasting in the unilateral group.

5. We observed that adverse effects like nausea, vomiting, pruritus, bradycardia, shivering, hypotension and respiratory depression were comparable in both the groups.
To conclude, unilateral spinal block when compared with bilateral spinal block, the haemodynamic changes were found statistically insignificant.

Unilateral spinal block (3 $\mathrm{mL}$ of $0.5 \%$ hyperbaric bupivacaine) provides early onset of sensory and motor block, dense motor block, increase in duration of postoperative analgesia and requirement of postoperative rescue analgesic was reduced.

\section{REFERENCES}

[1] Day M. Sympathetic blocks: the evidence. Pain Pract 2008;8(2):98-109.

[2] Pihlajamaki K, Kanto J, Lindberg R, et al. Extradural administration of bupivacaine: pharmacokinetics and metabolism in pregnant and non-pregnant women. $\mathrm{Br}$ J Anaesth 1990;64(5):556-62.

[3] Carpenter RI, Caplan RA, Brown DL, et al. Incidence and risk factors for side-effects of spinal anaesthesia. Anesthesiology 1992;76(6):906-16.

[4] Casati A, Fanelli G, Aldegheri G, et al. Frequency of hypotension during conventional or asymmetric hyperbaric spinal block. Reg Anesth Pain Med 1999;24(3):214-9.

[5] Fanelli G, Borghi B, Casati A, et al. Unilateral bupivacaine spinal anesthesia for outpatient knee arthroscopy. Italian Study Group on Unilateral Spinal Anesthesia. Can J Anaesth 2000;47(8):746-51.

[6] Liu SS, Ware PD, Allen HW, et al. Dose response characteristics of spinal bupivacaine in volunteers: clinical implications for ambulatory anesthesia. Anesthesiology 1996;85(4):729-36.

[7] Covert CR, Fox GS. Anesthesia for hip surgery in the elderly. Can J Anaesth 1989;36(3 Pt 1):311-9.

[8] Cousins MJ, Bridenbaugh PO, Carr DB, et al. Cousins and Bridenbaugh's neural blockade in clinical anesthesia and pain medicine. $4^{\text {th }}$ edn. Philadelphia, PA: Lippincott Williams \& Wilkins 2009: p. 1360.

[9] Almarakbi WA, Fawzi HM. Effect of three different doses of hyperbaric bupivacaine $0.5 \%$ in unilateral spinal anesthesia on cardiovascular parameters: a Nexfin monitor study. Ains Shams Journal of Anesthesiology 2013;6(1):63-8.

[10] Atef HM, El-Kasaby A, Omera M, et al. Optimal dose of hyperbaric bupivacaine $0.5 \%$ for unilateral spinal anesthesia during diagnostic knee arthroscopy. Local Reg Anesth 2010;3:85-91.

[11] Cicekci F, Yilmaz H, Balasar M, et al. Is unilateral spinal anesthesia superior to bilateral spinal anesthesia in unilateral inguinal regional surgery? M E J Anaesth 2014;22(6):591-6.

[12] Esmaoğlu A, Boyaci A, Ersoy 0, et al. Unilateral spinal anaesthesia with hyperbaric bupivacaine. Acta Anaesthesiol Scand 1998;42(9):1083-7.

[13] Kirdemir P, Marsan A, Kirdemir V. Comparison of hemodynamic and postoperative analgesic effects and recovery of unilateral and bilateral spinal anesthesia. Neurosciences (Riyadh) 2006;11(1):37-40. 